\title{
DESENVOLVIMENTO E TESTES DE UMA SEMEADORA-ADUBADORA MODULAR PARA PEQUENAS PROPRIEDADES RURAIS
}

\author{
LUCAS AREND ${ }^{1}$, FERNANDO A. FORCELLINI ${ }^{2}$, AUGUSTO WEISS ${ }^{3}$
}

RESUMO: O trabalho apresenta o desenvolvimento e testes de campo de equipamento agrícola modular. Para o desenvolvimento do equipamento, foi utilizada metodologia de projeto para sistemas modulares. $\mathrm{O}$ objetivo principal foi desenvolver um sistema modular que contribuísse para melhorar o atual quadro de mecanização agrícola da pequena propriedade rural, enfocando alguns dos equipamentos destinados às atividades conservacionistas de cultivo. Por ser modular, o equipamento atende às funções de semear-adubar, escarificar e sulcar o solo. Para a função semear-adubar, podem ser usados cinzéis e disco duplo para a semeadura; já para as funções de escarificação e sulcagem, podem ser usadas ferramentas específicas, facilmente intercambiadas em um chassi tubular principal. Os resultados para solo argiloso (Typic Oxisols), com umidade em torno de 20,5\% e massa seca de $11,5 \mathrm{t} \mathrm{ha}^{-1}$ para a variante semeadora-adubadora com duplo cinzel, foram satisfatórios com relação aos parâmetros de patinagem das rodas motoras, regularidade de distribuição em profundidade, cobertura das sementes, distribuição longitudinal das sementes e emergência de plantas.

PALAVRAS-CHAVE: semeadora-adubadora modular, plantio direto, testes de campo.

\section{DEVELOPMENT AND TEST OF A MODULAR SEEDER - FERTILIZER FOR SMALL COUNTRYSIDE PROPERTIES}

\begin{abstract}
This work presents the development and field tests of a modular agricultural implement. A Modular Design Product methodology was used for the implement development, and the main objective was the development of a modular system to improve the actual situation of mechanization on small countryside properties. The development focus was kept on some implements for conservative cultivation. For its modularity, the implement developed attained the functions of seeding - fertilizing, scarification and furrowing the soil. For the function of seeding-fertilizing can be used either narrow chisels or double disc, for the furrowing function a specific tool can be used. The main tubular chassis allowed an easily interchangeability between both functions (seed-season and furrowseason). The results for Typical Oxisoils with humidity around of $20.5 \%$ and dry mass of $11.5 \mathrm{t} \mathrm{ha}^{-1}$ for the aspect of seed-fertilize with double chisels were satisfactory, in relation with parameters like road skidding traction, deep regularity distribution, coverage and longitudinal distribution of the seeds and emerging plants.
\end{abstract}

KEYWORDS: modular seeder-fertilizer, direct seed, field test.

\section{INTRODUÇÃO}

Desenvolver produtos que atendam realmente às necessidades dos clientes finais, já não é uma atividade que possa ser delineada apenas pelo conhecimento de engenheiros e projetistas. $\mathrm{O}$ mercado exige soluções rápidas, inovadoras, condizentes com a real necessidade do cliente e/ou usuário e, principalmente, de baixo custo. Isso também é válido para a mecanização agrícola. As técnicas conservacionistas de cultivo estão avançando e sendo intensificadas em pequenas propriedades, mas é

\footnotetext{
${ }^{1}$ Engo Mecânico, Departamento de Engenharia Mecânica, Universidade Federal de Santa Catarina, lucas@ nedip.ufsc.br

${ }^{2}$ Prof. Dr., Departamento de Engenharia Mecânica, Universidade Federal de Santa Catarina, forcellini@emc.ufsc.br

${ }^{3}$ Prof. Dr., Departamento de Engenharia Rural, Universidade Federal de Santa Catarina, augusto@cca.ufsc.br

Recebido pelo Conselho Editorial em: 9-5-2003

Aprovado pelo Conselho Editorial em: 14-10-2005
} 
preciso adequar os implementos agrícolas a essa nova demanda. Constata-se que os próprios agricultores procuram adequar seus equipamentos as suas condições de trabalho, e essa prática se intensifica quando se trata de equipamentos envolvidos com plantio direto e cultivo mínimo. Surge, assim, a necessidade de desenvolver equipamentos adequados às condições dos pequenos agricultores, tanto do ponto de vista técnico quanto do econômico, pois o preço de aquisição desses equipamentos deve ser o menor possível, favorecendo o usuário final.

Este trabalho busca dar uma contribuição para a mecanização conservacionista da pequena propriedade, por meio do desenvolvimento de equipamento modular com tração animal. $\mathrm{O}$ equipamento modular desenvolvido pode ser configurado em quatro variantes que cobrem as tarefas de escarificação, sulcagem, semeadura e adubação com disco duplo e cinzel, e duplo cinzel. Para a configuração da semeadora-adubadora com duplo cinzel, foram realizados testes para verificar o desempenho operacional.

\section{MATERIAL E MÉTODOS}

O desenvolvimento do equipamento modular foi baseado na metodologia de projeto de sistemas modulares proposta por MARIBONDO (2000), envolvendo as fases de projeto informacional, conceitual, preliminar e detalhado. O desdobramento do processo de projeto envolveu o trabalho de duas dissertações de mestrado, sendo uma enfocando as primeiras fases (informacional e conceitual) (MAZETTO, 2000), e outra para as últimas fases (preliminar e detalhado) (AREND, 2003).

O trabalho iniciou-se com a definição de quatro equipamentos, selecionados a partir de um conjunto de dez, apontados como suficientes para a atividade de cultivo conservacionista em pequenas propriedades (WEISS, 1998). Em seguida, passou-se pela identificação dos desejos e necessidades dos futuros clientes e usuários do sistema a ser obtido, sendo identificadas as estruturas funcionais dos equipamentos envolvidos e chegando-se à definição dos módulos que compõem o equipamento modular.

Durante o desenvolvimento, foram aplicadas várias ferramentas de auxílio à tomada de decisão, tais como QFD (Desdobramento da Função Qualidade), Matriz Morfológica e Análise do Ciclo de Vida dos Produtos, além de novas ferramentas, como as denominadas Fichas Técnicas e a Matriz de Apoio à Escolha entre Módulos Funcionais (MAZETTO, 2000).

Como a função global a ser realizada pelo equipamento é cultivar solo, pode-se desdobrar essa função e definir as variantes funcionais do equipamento. Com esses equipamentos identificados e o devido desdobramento funcional de cada um, verificaram-se as funções que poderiam ser agrupadas, formando, assim, os módulos construtivos. Com isso, foi utilizado o método da matriz morfológica para desenvolver princípios de soluções que atendam às funções primordiais de cada módulo. Com vários princípios de soluções gerados, esses foram combinados, formando concepções que foram avaliadas em relação aos requisitos de projeto, a fim de escolher a mais promissora e que será desenvolvida. Para a concepção escolhida, usaram-se alguns módulos disponíveis comercialmente e outros foram projetados para atender especificidades das variantes, formando os módulos básicos e os módulos especiais. As variantes obtidas foram: variante 1 - sulcador; variante 2 - semeadoraadubadora com cinzel; variante 3 - escarificador, e variante 4 - semeadora-adubadora com disco duplo.

Com a concepção do equipamento modular desenvolvida, as especificações de projeto e os requisitos de projeto estabelecidos, iniciou-se o projeto preliminar. Assim, foi definida a arquitetura do equipamento modular, para as quatro variantes da função global mostrada na Figura 1.

Durante o projeto preliminar, foram realizados estudos para a verificação da ergonomia, sendo realizadas a modelagem e a simulação, aplicando o método DFA (projeto para montagem), método DFM (projeto para manufatura) e aplicando FMEA (análise dos modos de falha e seus efeitos). É importante mencionar que todas as análises, soluções e alternativas geradas foram devidamente 
controladas para atenderem às especificações de projeto geradas na fase informacional (AREND, 2003).

A aplicação da metodologia envolveu uma atividade denominada desenvolvimento de um protótipo, na qual, além do planejamento e fabricação do mesmo, foi realizado o planejamento dos testes para a variante semeadora-adubadora com duplo cinzel.

ESCARIFICADOR

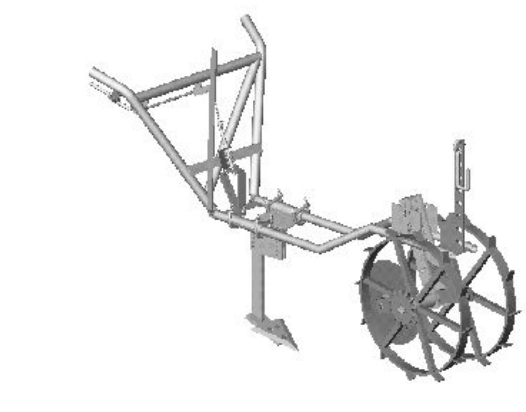

SEMEADORA-ADUBADORA COM DUPLO CINZEL

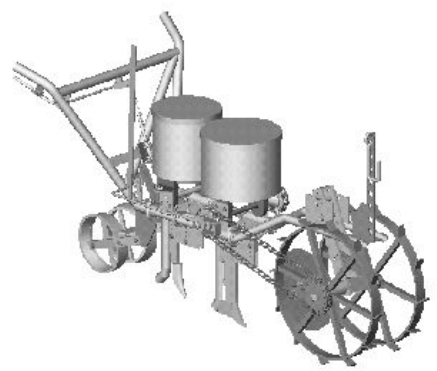

SEMEADORA-ADUBADORA COM CINZEL E DUPLO DISCO

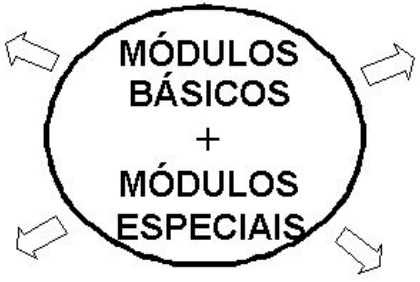

SULCADOR

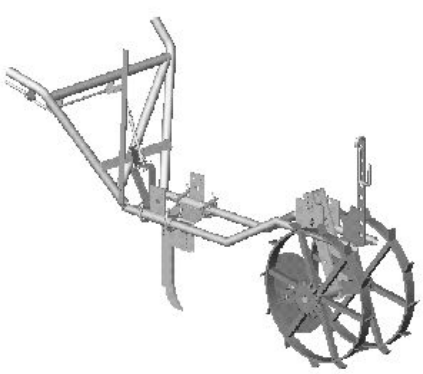

FIGURA 1. Representação do equipamento modular desenvolvido (AREND, 2003).

Por fim, a fase de projeto detalhado finaliza a aplicação da metodologia e do processo de projeto em que, por meio das melhorias sugeridas nos testes, são efetuadas as atualizações, finalizações de desenhos e especificações das partes, materiais, custos e materiais de suporte, providenciando toda a documentação necessária para a fabricação.

Os testes foram realizados numa área localizada no município de Ernestina - RS, pertencente à unidade de mapeamento em Passo Fundo - RS, classificado como Latossolo Vermelho distroférrico (Typic Oxisols), de textura argilosa, relevo ondulado, substrato basalto. Os testes foram conduzidos sobre resteva de milho, com valor médio de massa seca de $11,5 \mathrm{t} \mathrm{ha}^{-1}$. A umidade média percentual do solo era de $21 \%$ e $20 \%$ a $10 \mathrm{~cm}$ e a $20 \mathrm{~cm}$, respectivamente, no dia da realização dos testes.

Para os ensaios, foi utilizada área de $960 \mathrm{~m}^{2}$ (80 x $\left.12 \mathrm{~m}\right)$, empregando sementes fiscalizadas de milho híbrido Pioneer, com padrões mínimos de pureza de $98 \%$, germinação de $85 \%$ e peneira C20. O adubo empregado no teste foi NPK, 20-25-25, sendo os reservatórios mantidos constantemente com $50 \%$ da sua capacidade, ou seja, $3 \mathrm{~kg}$ de semente e $5 \mathrm{~kg}$ de adubo. A velocidade de deslocamento do equipamento durante os testes foi $5 \mathrm{~km} \mathrm{~h}^{-1}$. A fonte de tração foi um trator de $66 \mathrm{~kW}(90 \mathrm{cv}) \mathrm{de}$ potência, com engate na barra de tração. Os dosadores utilizados no equipamento foram de tipo disco horizontal para sementes e disco horizontal rotativo para o adubo, usuais no mercado.

Vale destacar que as avaliações tiveram por objetivo verificar de maneira inicial o comportamento de alguns parâmetros. Outras avaliações deverão ser realizadas com o objetivo de validar o equipamento desenvolvido. 
Os parâmetros selecionados para os testes, conforme orientações de MIALHE (1996) e ABNT (1995), foram: patinagem das rodas motoras, regularidade da distribuição em profundidade das sementes, cobertura das sementes e adubo, verificação da distribuição longitudinal de sementes e do índice de emergência de plantas.

$\mathrm{Na}$ área utilizada para os testes, foram definidas quatro linhas de plantio, as quais foram divididas em 12 parcelas, conforme Figura 2. Para cada parâmetro testado, foram alocadas aleatoriamente três parcelas para a realização das medições, conforme Tabela 1.

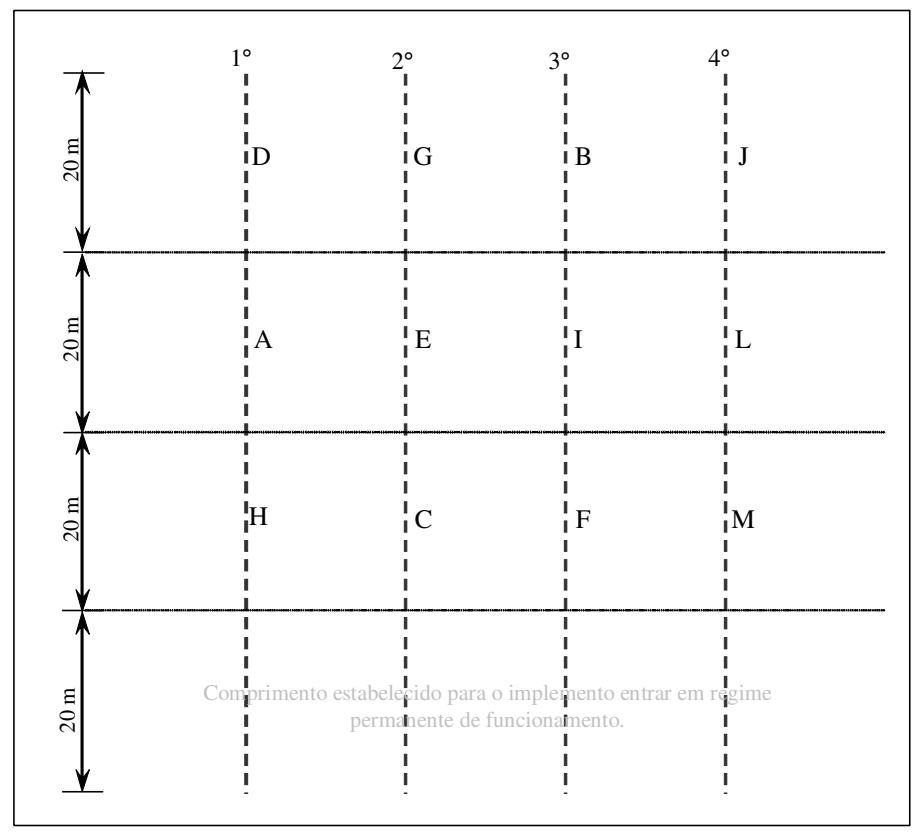

FIGURA 2. Divisão da área de testes em linhas e parcelas.

TABELA 1. Divisão das parcelas e linhas de plantio para o ensaio.

\begin{tabular}{ccl}
\hline Parcelas & Linhas & \multicolumn{1}{c}{ Parâmetros Verificados } \\
\hline A , B , C & $1^{\text {a }}$ & $\begin{array}{l}\text { Patinagem das rodas motoras, cobertura das sementes e adubo e } \\
\text { regularidade da distribuição em profundidade das sementes. }\end{array}$ \\
\hline D, E, F & $2^{2^{\mathrm{a}}}$ & $\begin{array}{l}\text { Revolvimento de cobertura vegetal no solo e verificação da } \\
\text { distribuição longitudinal das sementes. }\end{array}$ \\
\hline $\mathrm{G}, \mathrm{H}, \mathrm{I}$ & $3^{\mathrm{a}}$ & Verificação do índice de emergência de plântulas. \\
\hline J, L, M & $4^{\mathrm{a}}$ & Linha reserva. \\
\hline
\end{tabular}

O equipamento mostrado na Figura 3 apresenta as seguintes características dimensionais:

- Largura: $69 \mathrm{~cm}$;

- Comprimento: $150 \mathrm{~cm}$;

- Altura: $80 \mathrm{~cm}, \mathrm{e}$

- Massa total da semeadora-adubadora vazia: $76 \mathrm{~kg}$. 


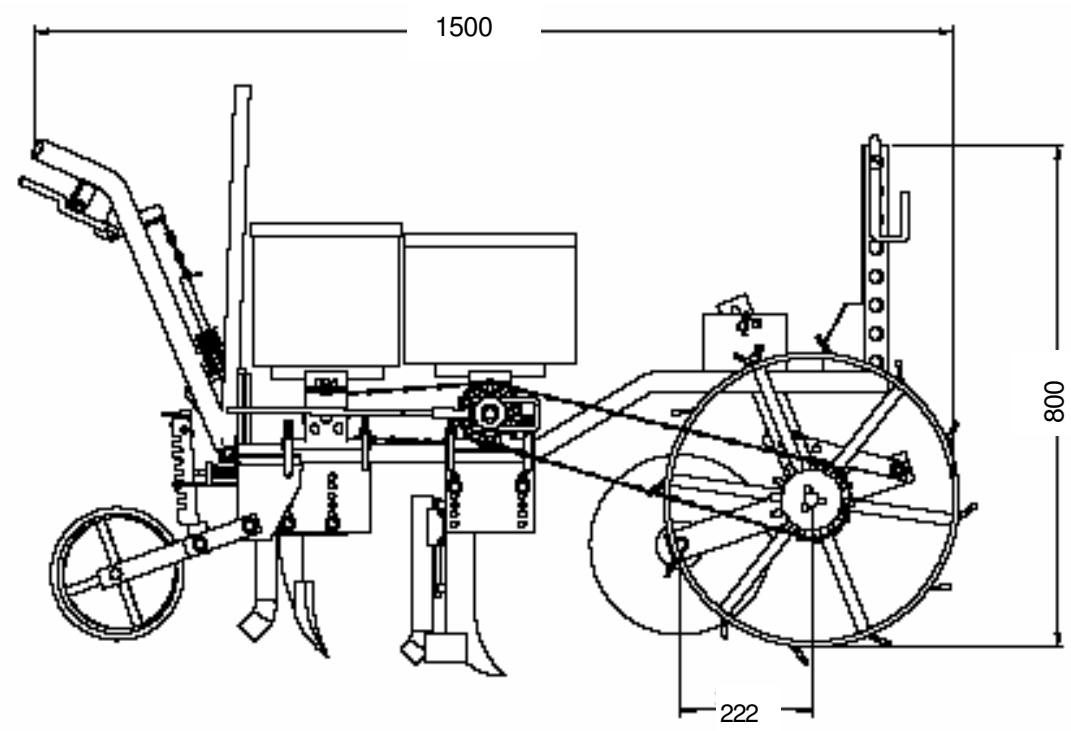

FIGURA 3. Vista lateral do equipamento.

\section{RESULTADOS E DISCUSSÃO}

\section{Patinagem das rodas motoras}

Com esse parâmetro, buscou-se verificar se as rodas motoras estão dentro do padrão admissível de patinagem para semeadoras e, com isso, verificar se os dosadores estão recebendo a rotação adequada para executar suas funções.

Contou-se o número de voltas realizado pela roda, medindo-se o comprimento real percorrido entre os $20 \mathrm{~m}$ de cada parcela, fazendo a posterior relação das variáveis. Valores típicos admissíveis de patinagem das rodas, segundo WEBER et al. (2001), são de 3,2 a 8,8\%. Os resultados desse parâmetro (Tabela 2) mostram que a média das patinagens percentuais ficou num patamar muito próximo do limite superior aceitável, ou seja, 3,2 7,97 $<8,8$. A grande quantidade de massa seca da resteva de milho, em torno de $11,5 \mathrm{t} \mathrm{ha}^{-1}$, pode ter contribuído com o aumento da patinagem.

TABELA 2. Resultados do teste de patinagem das rodas motoras.

\begin{tabular}{cccc}
\hline Parcelas & $\begin{array}{c}\text { Medido } \\
\left(\mathrm{n}^{\mathrm{o}} \text { de voltas }\right)\end{array}$ & $\begin{array}{c}\text { Teórico } \\
\left(\mathrm{n}^{\mathrm{o}} \text { de voltas }\right)\end{array}$ & Patinagem $(\%)$ \\
\hline $\mathrm{A}$ & 8 & 8,55 & 6,43 \\
$\mathrm{~B}$ & 9 & 9,84 & 8,54 \\
$\mathrm{C}$ & 11 & 12,08 & 8,94 \\
\hline Média & & & 7,97 \\
\hline
\end{tabular}

\section{Regularidade da distribuição em profundidade das sementes}

O objetivo foi verificar a profundidade de abertura do sulco para a deposição de sementes, ou seja, a profundidade em que essas são depositadas e sua regularidade. A profundidade recomendada para as sementes de milho é de, no máximo, $5 \mathrm{~cm}$, devendo o adubo ficar abaixo das mesmas. Para três diferentes parcelas, escolheram-se aleatoriamente comprimentos de $2 \mathrm{~m}$, para os quais foram medidas as profundidades de deposição das sementes. A profundidade de deposição das sementes foi regulada para $5 \mathrm{~cm}$. Na Tabela 3, estão apresentados os resultados das medições. 
Os resultados obtidos mostram que, na média, os valores de profundidade ficaram de acordo com a regulagem utilizada. Verificou-se, também, que a profundidade de deposição do adubo acompanhou as profundidades das sementes, ficando abaixo das mesmas, não ocorrendo mistura entre adubo e sementes.

TABELA 3. Profundidade da deposição das sementes com 12 medições (sementes) em 2 m para cada parcela.

\begin{tabular}{cccc}
\hline Medições & Parcela E $(\mathrm{cm})$ & Parcela F $(\mathrm{cm})$ & Parcela J $(\mathrm{cm})$ \\
\hline 1 & 5,0 & 5,5 & 5,0 \\
2 & 5,0 & 4,8 & 4,5 \\
3 & 4,5 & 5,0 & 5,3 \\
4 & 5,3 & 5,0 & 4,5 \\
5 & 5,2 & 5,3 & 5,0 \\
6 & 4,6 & 5,0 & 5,5 \\
7 & 4,8 & 4,8 & 5,4 \\
8 & 5,4 & 4,9 & 4,5 \\
9 & 5,3 & 5,2 & 5,2 \\
10 & 5,0 & 5,0 & 4,9 \\
11 & 5,0 & 5,0 & 4,7 \\
12 & 5,0 & (falha) & 5,2 \\
\hline Média $(\mathrm{cm})$ & 5,0 & 5,05 & 4,97 \\
\hline
\end{tabular}

\section{Cobertura das sementes e adubo (fechamento do sulco)}

Com esse teste, foi verificado se as sementes e o adubo ficaram devidamente cobertos após a semeadura. Para três diferentes parcelas, foram contadas as sementes não-cobertas após a semeadura nos $20 \mathrm{~m}$ de comprimento dessas parcelas. Os resultados da contagem estão apresentados na Tabela 4.

O equipamento foi regulado para depositar seis sementes por metro. Com base nos resultados obtidos, verificou-se que a cobertura das sementes é considerada satisfatória.

TABELA 4. Cobertura das sementes.

\begin{tabular}{cccc}
\hline Parcelas $(20 \mathrm{~m})$ & $\begin{array}{c}\text { População Teórica } \\
\text { (sem.) }\end{array}$ & Sementes Cobertas (em 20 m) & $\begin{array}{c}\text { Índice de Cobertura das } \\
\text { Sementes }(\%)\end{array}$ \\
\hline A & 120 & 118,0 & 98,33 \\
B & 120 & 118,0 & 98,33 \\
C & 120 & 119,0 & 99,17 \\
\hline Média & & 118,3 & 98,61 \\
\hline
\end{tabular}

\section{Verificação da distribuição longitudinal das sementes e do índice de emergência de plântulas}

A verificação da germinação das sementes, dos espaçamentos entre as plantas, bem como, a germinação obtida para a quantidade de sementes depositadas foi realizada 19 dias após a semeadura. Levantou-se o número de ocorrências de deposição de múltiplos, falhos e aceitáveis, e compararam-se esses números com as recomendações agronômicas do espaçamento entre sementes para a cultura utilizada, de acordo com a norma ABNT (1995), milho espaçamento de 12,5 - 16,5 cm. Na Tabela 5, apresentam-se os intervalos obtidos, utilizando-se de 16,5 cm como espaçamento-referência (Xref).

O resultado final dos espaços entre as sementes, para múltiplos, aceitáveis e falhas na cultura de milho, está apresentado na Tabela 6. 
TABELA 5. Intervalos de referência para os espaçamentos (ABNT, 1995).

\begin{tabular}{cc}
\hline Tipo de Espaçamento & Intervalo de Tolerância para "X" \\
\hline Múltiplos $<0,5$ Xref) & $\mathrm{X}<8,25$ \\
0,5 Xref $<$ Aceitáveis $>1,5$ Xref & $8,25<\mathrm{X}>24,75$ \\
Falhas $>1,5$ Xref & $\mathrm{X}>24,75$ \\
\hline
\end{tabular}

De acordo com MIALHE (1996), os espaçamentos aceitáveis devem ficar no mínimo em 60\% do total, sendo verificado que, nas três parcelas do teste, obtiveram-se valores de espaçamentos aceitáveis acima do recomendado, o que é mais significativo. O percentual restante para cada parcela são as ocorrências de espaçamentos múltiplos e falhas, sendo verificada maior ocorrência das últimas. Um dos fatores que podem ter contribuído para a ocorrência dessas falhas, foi o comprimento excessivo do cano condutor de sementes $(400 \mathrm{~mm})$, podendo ocasionar o repique de sementes no mesmo durante a semeadura.

TABELA 6. Resultados da distribuição longitudinal das sementes e germinação em três parcelas com $10 \mathrm{~m}$ cada e total de 179 leituras.

\begin{tabular}{clll}
\hline Parcelas & E & \multicolumn{1}{c}{ F } & J \\
\hline Múltiplos (\%) & 14,12 & 10,20 & 4,12 \\
Aceitáveis (\%) & 65,31 & 69,39 & 73,47 \\
Falhas (\%) & 20,57 & 20,41 & 22,41 \\
Média (cm) & 20,29 & 13,39 & 22,90 \\
Germinação Teórica (\%) & 85 & 85 & 85 \\
Germinação Verificada (\%) & 96 & 98 & 98 \\
\hline
\end{tabular}

\section{CONCLUSÕES}

A utilização de metodologia de projeto no desenvolvimento do equipamento foi determinante para a obtenção das configurações que formam a família de produtos modulares.

A configuração modular do sistema desenvolvido permite o compartilhamento de módulos, tornando fácil a mudança de função do equipamento, possibilitando o aumento de suas capacidades e melhorando o desempenho em termos da manutenção e reposição de peças.

A característica de flexibilidade da configuração modular não comprometeu o desempenho funcional da variante semeadora-adubadora com disco de corte e duplo cinzel.

\section{AGRADECIMENTOS}

Ao CNPq, à FINEP, à IADEL - Máquinas e Implementos, ao Sr. Beno Gnich, ao Sr. André Arend e a Luiz A. S. Guardini, pelos apoios na execução deste trabalho.

\section{REFERÊNCIAS}

AREND, L. Sistematização das fases de projeto preliminar e detalhado do desenvolvimento de produtos e sua aplicação no domínio máquinas agrícolas. 2003. 235 f. Dissertação (Mestrado em Engenharia Mecânica) - Universidade Federal de Santa Catarina, Florianópolis, 2003.

ASSOCIAÇÃO BRASILEIRA DE NORMAS TÉCNICAS. Projeto de norma 04:015.06-007: semeadora - semeadora-adubadora - ensaios de campo - método de ensaio. São Paulo, 1995. 12 p.

MARIBONDO, J.F. Desenvolvimento de uma metodologia de projeto de sistemas modulares, aplicada a unidades de processamento de resíduos sólidos domiciliares. 2000. 264 f. Tese (Doutorado em Engenharia Mecânica) - Universidade Federal de Santa Catarina, Florianópolis, 2000. 
MAZETTO, G.M. Desenvolvimento de um sistema modular para mecanização agrícola conservacionista em pequenas propriedades. 2000. 127 f. Dissertação (Mestrado em Engenharia Mecânica) - Universidade Federal de Santa Catarina, Florianópolis, 2000.

MIALHE, L.G. Máquinas agrícolas: ensaio \& certificação. Piracicaba: Fundação de Estudos Agrários “Luiz de Queiroz", 1996. 722 p.

WEBER, C.J.; GALLINA, F.; REIS, A.V.dos; FORCELLINI, F.A. Modelamento e simulação dos erros da cadeia cinemática de acionamento e do disco dosador em semeadoras de precisão. In: CONGRESSO BRASILEIRO DE ENGENHARIA AGRÍCOLA, 30., 2001, Foz do Iguaçu. Anais... Cascavel: Sociedade Brasileira de Engenharia Agrícola, 2001. 1 CD-ROM.

WEISS, A. Desenvolvimento e adequação de implementos para a mecanização agrícola conservacionista em pequenas propriedades. 1998. 209 f. Tese (Doutorado em Engenharia de Produção) - Universidade Federal de Santa Catarina, Florianópolis, 1998. 